\title{
Socioeconomic Position in Childhood and Adult Cardiovascular Mortality in 1971-98 in Finland - Register-Based Follow-Up Study of a Large Sample from the 1950 Census
}

\author{
VEIJO NOTKOLA, Ph.D., General Manager ${ }^{1}$ \\ TUIJA MARTELIN, Ph.D., Senior Researcher ${ }^{2}$ \\ SEPPO KOSKINEN, Ph.D., Chief Physician ${ }^{2}$ \\ ${ }^{1}$ Rehabilitation Foundation Helsinki, Finland \\ ${ }^{2}$ National Public Health Institute (KTL), Department of Health and Functional \\ Capacity, Helsinki, Finland
}

\begin{abstract}
The purpose of the study was to analyse the relative importance of socioeconomic conditions in childhood and adulthood as predictors of cardiovascular mortality in adulthood. The study is based on a 10\% sample of the 1950 Finnish census, linked individually to information from the censuses of 1970-95 and to deaths during 1971-98. Subjects aged 7-13 years living with their parents in 1950 were included. Parent's occupational class in 1950 and the subject's own occupational class in 1970 were used as measures of socioeconomic position in childhood and adulthood. The main statistical method used was the Cox proportional hazards model.
\end{abstract}

Socioeconomic conditions in childhood and adulthood were independent predictors of adult cardiovascular mortality in both sexes and of non-cardiovascular mortality among men. The effect of parent's occupational class on mortality was systematic and graded. The results suggest that the impact of living conditions in childhood on adult mortality is not restricted to the effects of absolute poverty and undernutrition. 


\section{Introduction}

During the late 1980s and the 1990s a vivid scientific discussion has been going on concerning the relative importance of circumstances during different phases of the life course as determinants of health in adulthood and older age (Harris 2001). Increasing interest has been focused on the role of the fetal period and childhood in determining adult health. The hypothesis of biological programming, introduced by David Barker and his colleagues, suggests that certain stimuli, such as undernutrition, during critical periods in utero or in early infancy have lifelong effects on an individual's health (e.g. Barker and Osmond 1986; Barker 1992; Barker 1998). A related hypothesis was put forward earlier by Forsdahl (1977).

The emphasis has been on ischaemic heart disease and other cardiovascular diseases (e.g. Burr and Sweetnam 1980; Barker and Osmond 1986; Vågerö and Leon 1994;

Wannamethee et al. 1996), but there is evidence that poor living conditions during childhood also are associated with an increased risk of poor general health (Lundberg 1993; Rahkonen, Lahelma and Huuhka 1997; Bosma, Mheen and Mackenbach 1999), as well as many other diseases in adulthood, such as chronic bronchitis (Barker 1992), lung cancer (Forsdahl 1977), stomach cancer and stroke (Davey Smith et al. 1998), several infectious diseases (Elo and Preston 1992), and schizophrenia (Barker 1990).

The hypothesis that poor living conditions during childhood predict poor health and cardiovascular death in adulthood has gained support also from Finnish studies (Notkola et al. 1985; Kaplan and Salonen 1990; Lynch et al. 1994; Rantakallio et al. 1997; Eriksson et al. 1999). According to Notkola's results, concerning men born in 1900-1919, poor living conditions in childhood were associated with high mortality from cardiovascular diseases in adulthood even when the effects of lifestyle factors and socioeconomic position in adulthood were taken into account. (Notkola 1985; Notkola et al. 1985). This effect, however, was found only in Eastern Finland. Mortality from other than cardiovascular causes was not associated with living conditions in childhood. Also, according to Kaplan and Salonen (1990), socioeconomic status in childhood in Eastern Finland was significantly associated with ischaemic heart disease in middle-aged men. Furthermore, findings from another Finnish data set suggest that death from coronary heart disease may be a consequence of poor prenatal nutrition followed by improved postnatal nutrition (Erikson et al. 1999).

Some results and interpretations have questioned the hypothesis about a significant impact of childhood living conditions on adult mortality. In particular, research pertaining to the effects of early life conditions on adult health has been frequently criticised for not controlling for confounding factors, such as living conditions during adulthood (Ben-Shlomo and Davey Smith 1991; Elford, Whincup and 
Shaper1991; Elford, Shaper and Whincup 1992; Elo and Preston 1992; Paneth and Susser 1995; Joseph and Kramer 1996; Kannisto, Christensen and Vaupel 1997). So far, no consensus has been reached about the relative importance of early living conditions as compared to the conditions at later stages of life. To correctly assess the role of different factors, the accumulation and interaction of exposures during a person's entire life course as well as the interactions between them should be taken into account (e.g. Ben-Shlomo and Davey Smith 1991; Lundberg 1993; Lynch et al. 1994; Kuh et al. 1997; Rahkonen et al. 1997; Davey Smith et al. 1997, 1998; Wamala et al. 2001).

This study aims to assess the relative importance of socioeconomic conditions in childhood as predictors of cardiovascular mortality in adulthood in Finland among persons born in 1937-43. Earlier research on the impact of early living conditions on adult health, in Finland and predominantly also elsewhere, has only focused on men. In this study, mortality of women is also analysed.

\section{Data and methods}

The study is based on a large data set constructed by first computerising a $10 \%$ sample of the 1950 Finnish census and then linking it with data from the Longitudinal Census Data File, including information from the censuses carried out in 1970-95, and to the registers on causes of death in 1971-98. As the personal identification codes were not in use prior to the 1960 s, they had to be determined for each individual included in the 1950 census sample in order to enable their linkage to the other registers. Of the total sample, $73.1 \%$ could be linked to the Longitudinal Census Data File, which is quite close to the estimated theoretical maximum, allowing for deaths and emigration between 1950 and 1970 (Statistics Finland 1997).

Data on all members of the household were included on the same census form in 1950. The socioeconomic position of the child was defined on the basis of the occupational class of the head of the household. In most cases the head of household was also the main breadwinner of the family and the father of the child. Children aged 7-13 who lived with their parents in 1950 were included in this study. In 1950, the proportion of children living somewhere else than with their parents started to increase after the age of 13. The subject's own occupational class at the end of 1970 , i.e. at the age of $27-33$, was used as the indicator of socioeconomic position in adulthood. Due to differences in the census questionnaires in 1950 and in 1970, the classifications of the two socioeconomic variables are not exactly identical. In 1950 , the farming population was quite large, and it was further classified into three groups according to arable land. For the 1970 data this could not be done. In 1970, 
the manual workers who were not employed in agriculture were divided into skilled and unskilled categories.

The final data set includes only those subjects who were identified in the 1970 census and who were either still alive and could be identified at the 1995 census or who were known to have died in 1971-98. The number of persons belonging to these cohorts was 24923 men and 24068 women. The distribution of the study population according to gender and the two socioeconomic variables is given in Table 1. Substantial differences can be seen between the distributions according to socioeconomic indicators. In $1950,37 \%$ of the study population were living in farming families whereas in 1970 only $8 \%$ of them were farmers. By contrast, the proportion of non-manual employees was much higher in 1970 than in 1950. In 1970, also the group "other, unknown" was quite large, consisting mainly of students.

Table 1. The distribution of the study population by parent's occupational class in 1950 and one's own occupational class in 1970.

\begin{tabular}{lrrrr}
\hline & $\begin{array}{c}\text { Men } \\
\text { (N) }\end{array}$ & $\begin{array}{c}\text { Women } \\
(\mathbf{N})\end{array}$ & $\begin{array}{c}\text { All } \\
\text { (N) }\end{array}$ & (\%) \\
\hline Parent's occupational class in 1950 & & & & \\
Non-manual & 3431 & 3265 & 6696 & 13.8 \\
Manual & 7312 & 7056 & 14368 & 29.3 \\
Manual, agriculture or forestry work & 2149 & 2101 & 4250 & 8.7 \\
Farmer, 0-4 hectares & 4056 & 4051 & 8107 & 16.6 \\
Farmer, 5-9 hectares & 2894 & 2817 & 5711 & 11.7 \\
Farmer, 10+ hectares & 2444 & 2293 & 4737 & 9.8 \\
Other self-employed & 1965 & 1810 & 3775 & 7.7 \\
Other, unknown & 672 & 675 & 1347 & 2.8 \\
& & & & \\
One's own occupational class in 1970 & & & & \\
Non-manual & & & & \\
Skilled manual & 6747 & 9885 & 16632 & 34.0 \\
Unskilled manual & 8810 & 4992 & 13802 & 28.2 \\
Manual, agriculture or forestry work & 1144 & 1241 & 2385 & 4.9 \\
Farmer & 862 & 259 & 1121 & 2.3 \\
Other self-employed & 1916 & 1950 & 3866 & 7.9 \\
Other, unknown & 978 & 948 & 1926 & 3.9 \\
& 4466 & 4793 & 9259 & 18.9 \\
\hline
\end{tabular}

In this study, mortality from cardiovascular diseases and other causes of death is analysed. The classification of causes of death is based on the short list of causes of death used in time series from 1969 onwards (Statistics Finland 1999, Appendix 2A). Mortality follow-up started when the subjects turned 35, i.e. at the beginning of 1972 for the oldest subjects and at the beginning of 1978 for the youngest 
subjects, and ended at the end of 1998 when the subjects were 55-62 years old. During the follow-up, 965 cardiovascular deaths occurred among men and 238 among women. The number of deaths from other causes was 1963 and 881, respectively.

The main statistical method used was the Cox proportional hazards model (Altman 1991). Separate analyses were performed for men and women. Two consecutive models were applied in the analysis of relative mortality differences. In the first model relative mortality ratios (relative hazards) were presented for the socioeconomic indicator in question. The second models gave mortality ratios adjusted for the subject's own occupational class or parent's occupational class.

\section{Results}

\section{Cardiovascular mortality}

Age-adjusted mortality from cardiovascular diseases varied significantly according to both socioeconomic indicators among both women and men (Table 2). According to parent's occupational class in 1950, cardiovascular mortality was highest in manual agriculture and forestry work, followed by other manual workers and small farmers. Particularly in women, also the small group "other, unknown" had high mortality. The lowest mortality was observed among children of non-manual employees and farmers with at least 10 hectares of cultivated land.

Differences in age-adjusted mortality were also very clear according to the subject's own occupational class in 1970. Among men, these mortality differences tended to be greater compared with the corresponding differences in women, and also compared with men's mortality differences by parent's occupational class. Mortality was highest among unskilled manual workers and lowest among non-manual employees and also, in the fairly large group of "other, unknown", representing mainly persons who were students in 1970 .

The adjustment for the subject's own occupational class in 1970 markedly reduced the mortality differences by parent's occupational class in 1950, and in general the mortality differences were no longer statistically significant. However, even after the adjustment for the subject's own adult occupational class, cardiovascular mortality among sons of manual workers in agriculture and forestry remained statistically significantly higher than among sons of non-manual employees. Furthermore, regarding parent's occupational class, there was a statistically significant mortality trend among the farming population, i.e. agriculture/forestry workers and farmers. 
The adjustment of parent's occupational class had only a very small influence on the mortality differences by one's own occupational class, and these differences remained also statistically significant. One's own occupational class in early adulthood appeared to be a stronger predictor of cardiovascular mortality than parent's occupational class.

\section{Mortality from other causes of death}

In other than cardiovascular mortality there were quite small differences among men according to parent's occupational class, particularly when one's own occupational class in early adulthood was adjusted for (Table 3). Among women, there was no consistent pattern of mortality variation according to parent's occupational class. The subject's own occupational class proved to be a very strong predictor of death from other causes than cardiovascular diseases.

\section{Conclusions}

In a representative sample of subjects born in 1937-43, parent's occupational class was associated with cardiovascular mortality in adulthood in 1971-1998 in Finland. Adjustment for own occupational class in early adulthood somewhat weakened this association, but it remained systematic and statistically significant. The mortality gradient was equally steep among women and men, which is a particularly important finding. All previous results from Finland and most results from other countries as well have only concerned men.

Among men, the results suggested a systematic effect of early living conditions on deaths from other than cardiovascular causes even after adjusting for adult occupational class. This result may imply that poor living conditions in childhood increase the risk of some non-cardiovascular causes of death as well. Mortality from stomach cancer and stroke, for example, has been found to be connected with adverse socioeconomic conditions in childhood (Davey Smith et al. 1998). A more detailed cause-specific mortality analysis is obviously needed, based on a larger number of deaths than were analysed in this study.

Among women, there were no signs of an association between parent's occupational class and adult mortality from other causes of death than cardiovascular diseases when the subject's own social position in adulthood was taken into account. It is possible that this lack of any association among women hides two opposite trends. British results suggest that less affluent conditions during childhood may protect against some non-smoking related cancers, which appear to be related to high calorie intake (e.g. Frankel et al. 1998; Gunnell et al. 1998). 
Table 3. Relative mortality (hazard ratio) from other causes of death than cardiovascular diseases in 1972-98 among men and women aged 35-62 according to parent's occupational class in 1950 and one's own occupational class in 1970 in Finland. Cohort born in 1937-43.

Men

\section{Parent's occupation in 1950}

1 Non-manual

2 Manual

3 Manual, agriculture/forestry

4 Farmer, 0-4 hectares

5 Farmer, 5-9 hectares

6 Farmer, 10+ hectares

7 Other self-employed

8 Other, unknown

Test for differences

Test for trend among groups 3-6

\section{One's own occupation in 1970}

1 Non-manual

2 Skilled manual

3 Unskilled manual

4 Manual, agriculture/forestry

5 Farmer

6 Other self-employed

7 Other, unknown

Test for differences

\section{Women}

\section{Parent's occupation in 1950}

1 Non-manual

2 Manual

3 Manual, agriculture/forestry

4 Farmer, 0-4 hectares

5 Farmer, 5-9 hectares

6 Farmers, 10+ hectares

7 Other self-employed

8 Other, unknown

Test for differences

Test for trend among groups 3-6

\section{One's own occupation in 1970}

1 Non-manual (Reference group)

2 Skilled manual

3 Unskilled manual

4 Manual, agriculture/forestry

5 Farmer

6 Other self-employed

7 Other, unknown

Test for differences

\author{
Adjusted for one's \\ own occupational class \\ 1.00
}

$1.26(1.08-1.48) \quad 1.12(0.95-1.32)$

$1.48(1.22-1.80) \quad 1.22(1.00-1.50)$

$1.15(0.96-1.37) \quad 0.98(0.81-1.18)$

$1.13(0.94-1.37) \quad 0.99(0.81-1.21)$

$0.85(0.68-1.06) \quad 0.75(0.60-0.95)$

$1.14(0.92-1.41) \quad 1.03(0.83-1.28)$

$1.42(1.06-1.89) \quad 1.21(0.90-1.61)$

$\mathrm{P}=0.000 \quad \mathrm{P}=0.107$

$\mathrm{P}=0.000 \quad \mathrm{P}=0.000$

\title{
Adjusted for
}

parent's occupational class

$$
\begin{aligned}
& 1.00 \\
& 1.40(1.24-1.58) \\
& 2.83(2.37-3.37) \\
& 1.61(1.27-2.05) \\
& 1.12(0.92-1.36) \\
& 1.11(0.86-1.44) \\
& 0.63(0.53-0.75) \\
& P=0.000
\end{aligned}
$$

1.00

$1.37(1.21-1.56)$

$2.73(2.28-3.27)$

$1.59(1.25-2.03)$

$1.25(1.02-1.55)$

$1.12(0.86-1.45)$

$0.62(0.52-0.74)$

$\mathrm{P}=0.000$

Adjusted for one's own occupational class

$$
\begin{aligned}
& 1.00 \\
& 1.02(0.81-1.28) \\
& 1.03(0.76-1.39) \\
& 1.09(0.85-1.39) \\
& 0.84(0.63-1.11) \\
& 1.03(0.77-1.37) \\
& 0.98(0.71-1.33) \\
& 0.99(0.63-1.54) \\
& P=0.766
\end{aligned}
$$$$
\mathrm{P}=0.483
$$

1.00

$0.94(0.75-1.18)$

$0.88(0.65-1.20)$

$0.96(0.74-1.24)$

$0.74(0.55-1.00)$

$0.93(0.69-1.24)$

$0.92(0.67-1.26)$

$0.92(0.58-1.45)$

$\mathrm{P}=0.927$

$\mathrm{P}=0.627$

\section{Adjusted for} parent's occupational class

1.00

$1.37(1.16-1.63)$

$1.66(1.28-2.15)$

$1.13(0.60-2.13)$

$1.15(0.89-1.49)$

$1.02(0.72-1.45)$

$0.39(0.30-0.51)$

$\mathrm{P}=0.000$ 
One's own adult socioeconomic position appeared to be a somewhat stronger predictor of cardiovascular mortality than parent's occupational class. The connection between current socioeconomic position and mortality was equally strong in cardiovascular diseases and other causes of death.

The data of this study was based on persons born in 1937-1943. During most of that period, Finland was involved in the Second World War. There is no evidence that socioeconomic mortality differentials among persons born during the Second World War are different compared with those among persons born before or after the Second World War (see e.g. Valkonen et al. 1993, 69). Also in Norway, analysis of two war cohorts and the first post-war cohort found little evidence of cohort effects on socioeconomic mortality differentials (Dahl and Kjærsgaard 1993).

The main result was that both among males and females, parents' occupational class was connected with increased mortality, from cardiovascular diseases in particular, after adjustment for occupational class in adulthood. In this study, socioeconomic conditions in childhood referred to the situation during the 1940s and 1950s when absolute poverty was no longer very common in Finland. The mortality gradient according to parent's occupational class appeared to be systematic and monotonous. The lowest adult mortality was observed among children of farmers with large estates, as well as among daughters and sons of non-manual employees, and an increase in mortality was observed along with a decline in parents' socioeconomic position. Mortality was highest among children of manual workers employed in agriculture or forestry, i.e. one of the poorest subgroups of the Finnish population in the 1940s and 1950s. During the late 1930s and the early 1940s, the socioeconomic position of farm and forestry workers was probably the lowest in all of society, particularly in Eastern Finland. The situation of small farmers was not much better (Waris 1952; Haatanen 1968; Alestalo 1985). However, the systematic mortality gradient according to the socioeconomic position in childhood suggests that the impact of living conditions in childhood on adult mortality is not restricted to the effects of absolute poverty and undernutrition.

\section{References}

Alestalo M. 1985. Yhteiskuntaluokat ja sosiaaliset kerrostumat toisen maailmansodan jälkeen (in Finnish). In Valkonen T, R. Alapuro, M. Alestalo, R. Jallinoja and T. Sandlund: Suomalaiset. Porvoo: WSOY.

Altman DG. 1991. Practical statistics for medical research. London: Chapman et Hall.

Barker DJP, ed. 1992. The Fetal and Infant Origins of Adult Disease. London: BMJ Publishing Group.

Barker DJP. 1998. Mothers, babies and health in later life. Edinburgh: Churchill Livingstone.

Barker DJP and C. Osmond. 1986. Infant mortality, childhood nutrition, and ischaemic heart disease in England and Wales. Lancet i:1077-81. 
Ben-Shlomo Y, and G. Davey Smith. 1991. Deprivation in infancy or in adult life: which is more important for mortality risk? Lancet 337:530-4.

Bosma H, HD van de Mheen and JP Mackenbach. 1999. Social class in childhood and general health in adulthood: questionnaire study of contribution of psychological attributes. British Medical Journal 318:18-22.

Burr ML and PM Sweetnam. 1980. Family size and paternal unemployment in relation to myocardial infarction. Journal of Epidemiology and Community Health 34:93-5.

Dahl E and P. Kjærsgaard. 1993. Trends in socioeconomic mortality differentials in postwar Norway: evidence and interpretaions. Sociology of Health \& Illness 15:587-611.

Davey Smith G, C Hart, D Blane, C Gillis and V. Hawthorne. 1997. Lifetime socioeconomic position and mortality: prospective observational study. British Medical Journal 314:54752.

Davey Smith G, C Hart, D Blane and D Hole. 1998. Adverse socioeconomic conditions in childhood and cause-specific adult mortality: prospective observational study. British Medical Journal 316:1631-5.

Elford J, AG Shaper and P Whincup. 1992. Early life experience and cardiovascular disease - ecological studies. Journal of Epidemiology and Community Health 46:1-11.

Elford J, P Whincup and AG Shaper. 1991. Early life experience and adult cardiovascular disease: longitudinal and case-control studies. International Journal of Epidemiology 20:833-44.

Elo IT and SH Preston. 1992. Effects of early-life conditions on adult mortality: a review. Population Index 58 (2):186-212.

Eriksson JG, T Forsen, J Tuomilehto, PD Winter, C Osmond and DJ Barker. 1999. Catchup growth in childhood and death from coronary heart disease: longitudinal study. British Medical Journal 318:427-31.

Forsdahl A. 1977. Are poor living conditions in childhood and adolescence an important risk factor for arteriosclerotic heart disease? British Journal of Preventive and Social Medicine 31:91-5.

Frankel S, DJ Gunnell, TJ Peters, M Maynard, G Davey Smith. 1998. Childhood energy intake and adult mortality from cancer: the Boyd Orr cohort study. British Medical Journal 316:499-504.

Gunnell DJ, G Davey Smith, JMP Holly, S Frankel. 1998. Leg length and risk of cancer in the Boyd Orr Cohort. British Medical Journal 317:1350-1.

Haatanen P. 1968. Suomen maalaisväestö tutkimusten ja kaunokirjallisuuden valossa (in Finnish). Porvoo. WSOY.

Haatanen P. 1968. Suomen maalaisköyhälistö (In Finnish). Porvoo. WSOY.

Harris B. 2001. Commentary: 'The Child is father of the man.' The relationship between child health and adult mortality in the $19^{\text {th }}$ and $20^{\text {th }}$ centuries. International Journal of Epidemiology 30:688-96.

Joseph KS and MS Kramer. 1996. Review of the evidence on fetal and early childhood antecedents of adult chronic disease. Epidemiological Reviews 18:158-74.

Kannisto V, K Christensen and JW Vaupel. 1997. No increased mortality in later life for cohorts born during famine. American Journal of Epidemiology 45:987-94.

Kaplan GA and JT Salonen. 1990. Socioeconomic conditions in childhood and ischaemic heart disease during middle life. British Medical Journal 301:1121-3.

Kuh D, C Power, D Blane and M Bartley. 1997. Social pathways between childhood and adult health. In: A Life Course Approach to Chronic Disease Epidemiology, edited by Kuh D and Ben-Shlomo Y, pp. 169-98. Oxford: Oxford University Press.

Lundberg O. 1993. The impact of childhood living conditions on illness and mortality in adulthood. Social Science \& Medicine 36:1047-52. 
Lynch JW, GA Kaplan, RD Cohen, J Kauhanen, TW Wilson, NL Smith and JT Salonen. 1994. Childhood and adult socioeconomic status as predictors of mortality in Finland. Lancet 343:524-7.

Notkola V. 1985. Living conditions in childhood and coronary heart disease in adulthood. A mortality and morbidity study in two areas of Finland. Helsinki: Societas Scientiarum Fennica 29. The Finnish Society of Sciences and Letters.

Notkola V, S Punsar, MJ Karvonen and J Haapakoski. 1985. Socio-economic conditions in childhood and mortality and morbidity caused by coronary heart disease in adulthood in rural Finland. Social Science \& Medicine 21:517-23.

Paneth N and M Susser. 1995. Early origin of coronary heart disease (the "Barker hypothesis"). British Medical Journal 310:411-12.

Rahkonen O, Lahelma E and Huuhka M. 1997. Past or present? Childhood living conditions and current socioeconomic status as determinants of adult health. Social Science \& Medicine 44:327-36.

Rantakallio P, P Jones, J Moring and L von Wendt. 1997. Association between central nervous system infections during childhood, adult onset schizophrenia and other psychoses: a 28-year follow-up. International Journal of Epidemiology 26:837-43.

Statistics Finland. 1997. The Finnish Longitudinal Census Data File. Helsinki: Statistics Finland.

Statistics Finland. 1999. Causes of Death 1997. Health 1993:3. Appendix 2A. Helsinki: Statistics Finland.

Valkonen T, T Martelin, A Rimpelä, V Notkola and S Savela. 1993. Socio-economic mortality differences in Finland 1981-90. Helsinki: Statistics Finland, Population 1993:1.

Vågerö D and D Leon. 1994. Effect of social class in childhood and adulthood on adult morbidity. Lancet 343:1224-5.

Wamala SP, J Lynch and GA Kaplan. 2001. Women's exposure to early and later life socioeconomic disadvantage and coronary heart disease risk: the Stockholm female coronary risk study. International Journal of Epidemiology 30:275-84.

Wannamethee SG, PH Whincup, G Shaper and M Walker. 1996. Influence of father's social class on cardiovascular disease in middle-aged men. Lancet 348:1259-63.

Waris H. 1952. Suomalaisen yhteiskunnan rakenne. Helsinki: Kustannusosakeyhtiö Otava. 